\title{
REVIEW
}

\section{Adult intussusception: case reports and review of literature}

\author{
S Yalamarthi, R C Smith
}

Postgrad Med J 2005;81:174-177. doi: 10.1136/pgmj.2004.022749

Adult intussusception occurs infrequently and differs from childhood intussusception in its presentation, aetiology, and treatment. Diagnosis can be delayed because of its longstanding, intermittent, and non-specific symptoms and most cases are diagnosed at emergency laparotomy. With more frequent use of computed tomography in the evaluation of patients with abdominal pain, the condition can be diagnosed more reliably. Treatment entails simple bowel resection in most cases. Reduction of the intussusception before resection is controversial, but there is a shift against this, especially in colonic cases. Surgical treatment can be difficult in gastroduodenal and coloanal intussusceptions, sometimes requiring innovative techniques. This paper presents the diagnosis and management of four cases of adult intussusception, followed by review of the literature.

See end of article for authors' affiliations

Correspondence to: Mr S Yalamarthi, Department of General Surgery, Warrington Hospital, Lovely Lane, Warrington, Oheshire WA5 IQG, UK satyalam@aol.com

Submitted 11 April 2004 Accepted 14 June 2004 probably be labelled as having irritable syndrome. Although the surgical treatment is straightforward in most cases, in some patients, in particular those with gastroduodenal and coloanal intussusception, the operative aspect can be challenging.

We present four case reports followed by a literature review.

\section{CASE REPORTS \\ Case 1}

A 42 year old man was referred by his general practitioner with a three day history of melena. He had been investigated previously for iron deficiency anaemia for which no cause was found. His haemoglobin was $86 \mathrm{~g} / \mathrm{l}$ with an iron deficiency picture. An upper gastrointestinal (GI) endoscopy showed minimal oesophagitis. He settled with conservative treatment and had a
When subsequently seen in the clinic, he reported episodic left upper quadrant discomfort. $\mathrm{He}$ remained anaemic (haemoglobin $98 \mathrm{~g} / \mathrm{l}$ ) despite taking iron supplements and did not have any overt blood loss.

A barium meal follow through showed distortion in the terminal ileum; thought to be extrinsic compression by sigmoid colon Subsequent computed tomography showed an abnormal area of thickened ileum with a target appearance (fig 1) and intra-luminal fat, consistent with an ileo-ileal intussusception.

At laparotomy the radiological findings were confirmed. A small bowel resection without reduction of the intussusception was performed. He made an uneventful postoperative recovery. Pathology showed the lead point to be a Meckel's diverticulum (fig 2) with a traumatic ulcer.

\section{Case 2}

A 71 year old woman was admitted as an emergency with coffee ground vomiting and intermittent, colicky abdominal pain. She had been investigated over the past 18 months for symptoms of intermittent central and left upper quadrant abdominal pain, vomiting, constipation, weight loss, and anorexia. Upper GI endoscopy on two occasions showed features of distal oesophagitis, a sliding hiatus hernia, and duodenitis with positive Helicobacter pylori on one occasion. Subsequent barium enema, abdominal ultrasound, and small bowel follow through were all normal and in view of this she was thought to have irritable bowel syndrome.

During the first 24 hours of admission a significant decrease in her haemoglobin concentrations, necessitated blood transfusion. A repeat upper GI endoscopy and a barium follow through examination were again unhelpful. She settled with conservative treatment. An outpatient small normal barium enema.

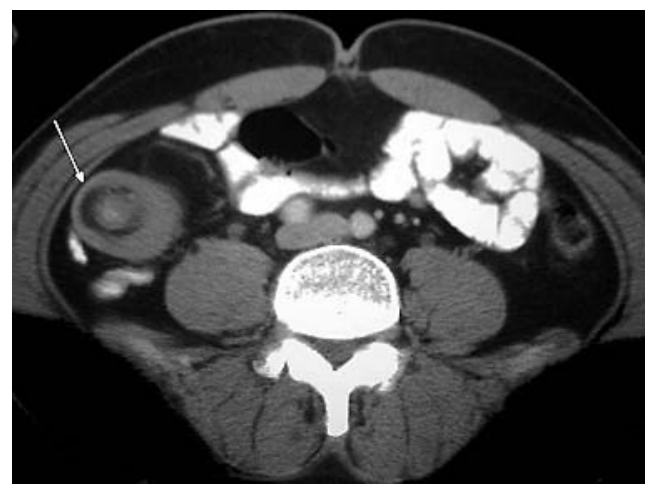

Figure 1 Abdominal computed tomogram showing a classic target lesion, suggesting ileo-ileal intussusception. 


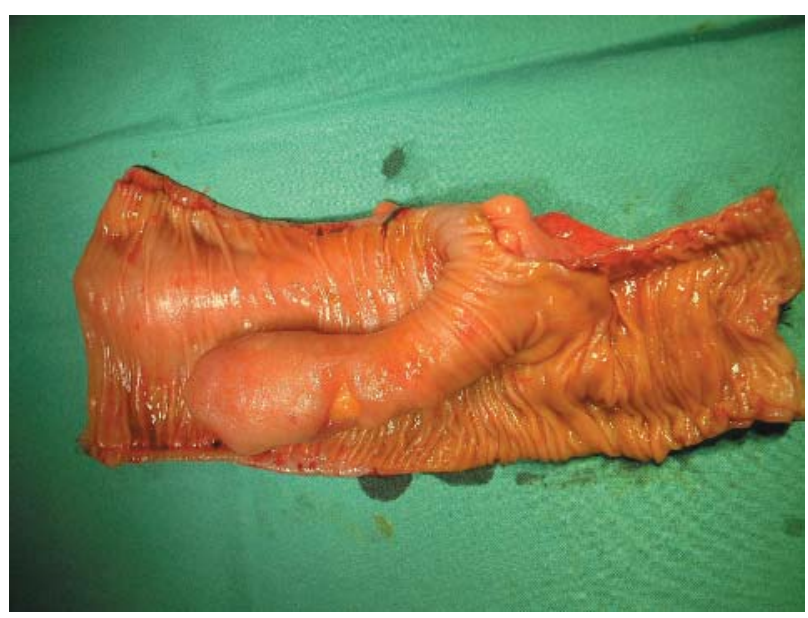

Figure 2 Resected specimen showing intussuscepting Meckel's diverticulum.

bowel follow through performed, was also normal. A computed tomogram of her abdomen was then obtained, which showed thickening of the jejunal mucosa and a soft tissue mass with a doughnut-like appearance in the left iliac fossa. The appearances were suspicious of a small bowel intussusception and a differential diagnosis of a lymphoma or carcinoma was considered.

At laparotomy an intussuscepting tumour of the mid-small bowel was seen. There was extensive fibrosis of the adjacent mesentery, thought to be attributable to the recurrent episodes of intussusception. A small bowel resection (without attempting a reduction) was carried out.

Postoperatively she made an uneventful recovery. Pathology of the resected specimen showed a $30 \mathrm{~mm}$ benign tubulovillous adenoma with mild dysplasia.

\section{Case 3}

A 48 year old man was referred to the surgical outpatient clinic with a three year history of heartburn, bloating, and regurgitation. His medical history included treatment for Helicobacter pylori. Abdominal examination was unremarkable apart from obesity.

Initial upper GI endoscopy showed a large sliding hiatus hernia, but the examination was incomplete because of large food residue. With a provisional diagnosis of pyloric stenosis, a subsequent barium meal was obtained, which showed a large filling defect in the second part of the duodenum with very little contrast passing beyond. Abdominal computed tomography showed a well circumscribed $6 \mathrm{~cm}$ duodenal mass, composed almost entirely of fat with some internal septations. A further upper GI endoscopy confirmed a large smooth polyp, which was obstructing the lumen of the duodenum. Biopsy specimens showed only normal duodenal mucosa.

At laparotomy a large irreducible antral mass that had intussuscepted into the duodenum was found. The second part of the duodenum was opened longitudinally; and the mass was shelled out. The duodenotomy was closed in two layers. Postoperatively the patient made an uneventful recovery. The pathology report confirmed the lesion to be a simple lipoma.

\section{Case 4}

An 84 year old woman residing in a nursing home presented with increasing confusion and a prolapsing mass through her anal canal. Over the previous year she had a history of recurrent episodes of non-specific abdominal pain and distension, which were short lasting and did not require hospital admission.

Examination of her abdomen showed slight distension with minimal tenderness. No masses were palpable. The perineum showed a prolapsing bowel with an irregular mass at the apex. Closer inspection confirmed that this was an intussusception rather than a prolapse and it was presumed to be a prolapse of a tumour of the sigmoid colon.

The intussusception was manually reduced. After appropriate resuscitation a midline laparotomy was carried out and the caecum was found to be the intussusceptum. Attempts to reduce this proved impossible, as the caecum could not be reduced out of the rectum. The anterior rectal wall was opened and the intussuscepting bowel was resected. Having removed the mass the two ends of bowel (ileum and transverse colon) could then be reduced and after trimming the bowel ends a functional end to end anastomosis was fashioned between the ileum and the transverse colon. The anterior rectal wall was repaired.

She made an uneventful recovery. The pathology report confirmed that the lesion causing the intussusception was a large villous adenoma of the caecum.

\section{DISCUSSION AND LITERATURE REVIEW}

The first report of intussusception was made in 1674 by Barbette of Amsterdam. ${ }^{6}$ Intussusception or "introsusception" as it was called then, was in addition detailed in 1789 by John Hunter. ${ }^{7}$ In 1871 Sir Jonathan Hutchinson was the first to successfully operate on a child with intussusception. ${ }^{8}$ Intussusception in adults differs from those in children in various aspects (table 1). ${ }^{9-13}$ In adults, $90 \%$ occur in the small or large bowel and, the remaining 10\% involve the stomach or a surgically created stoma. ${ }^{14}$ The single most common site is the small bowel. Coloanal intussusceptions are rare and usually occur in the setting of a benign or malignant tumour, ${ }^{15}$ with $50 \%$ attributable to a malignant lesion. It is important to differentiate this from rectal prolapse, which

Table 1 Differences between adult and childhood intussusceptions

\begin{tabular}{|c|c|c|}
\hline & Children & Adult \\
\hline Percentage of all intussusceptions & 95 & 5 \\
\hline Cause of intestinal obstruction & Frequent & $\begin{array}{l}\text { Rare }(<5 \% \text { of all intestinal } \\
\text { obstructions) }\end{array}$ \\
\hline Aetiology & $\begin{array}{l}\text { 90\%-idiopathic (Peyer's patch } \\
\text { enlargement in nearly 50\%) }\end{array}$ & $\begin{array}{l}\text { Rarely idiopathic. Cause identified in } \\
70 \%-90 \%\end{array}$ \\
\hline $\begin{array}{l}\text { Clinical symptoms (classic triad: } \\
\text { vomiting, rectal bleeding, and } \\
\text { abdominal pain) }\end{array}$ & Usually present & Occurs in only $15 \%-20 \%$ \\
\hline Treatment & $\begin{array}{l}\text { Mainly non-operative (barium } \\
\text { hydrostatic reduction) }\end{array}$ & $\begin{array}{l}\text { Surgical resection almost always } \\
\text { required }\end{array}$ \\
\hline
\end{tabular}


can be done by a careful clinical examination. In rectal prolapse continuity can be palpated between the perianal/ anal tissue and the protruding tissue, whereas in intussusception there is no palpable continuity and the finger can be freely passed between the anorectal wall and the prolapse throughout the circumference. Gastroduodenal intussusception, the least frequent of all, is usually caused by the prolapse of a benign gastric tumour into the duodenum, with subsequent invagination of a portion of the stomach wall. ${ }^{16}$

The lead points for the intussusceptions are attributable to benign, malignant, or idiopathic causes..$^{13}{ }^{14}$ Although all our four patients had a benign pathology, primary or secondary malignant lesions may account for $6 \%$ to $30 \%$ of all cases. In the review by Felix et al, ${ }^{17}$ tumour related intussusceptions were noted in $63 \%$ of cases.

Intussusception has also been noted in patients with tropical sprue/coeliac disease, ${ }^{17}$ abdominal trauma, ${ }^{18}$ and during the postoperative period. ${ }^{19}$ In addition, this condition has been noted increasingly among patients with AIDS related gut disease, which requires careful consideration. ${ }^{20}{ }^{21}$ Idiopathic intussusception in the small bowel accounts for $8 \%$ to $20 \%$ of all cases. ${ }^{917}$

The common intussusceptions have been classified into four categories according to the site of origin and they are: enteric, ileocolic, ileocaecal, and colonic. ${ }^{22}$ Enteric and colonic cases are those that are confined to the small and large intestine respectively. While ileocolic intussusceptions are those with prolapse of the ileum into the colon through the ileocaecal valve, ileocaecal intussusceptions occur when the ileocaecal valve acts as the lead point. However, in clinical practice it is difficult to differentiate between ileocolic and ileocaecal intussusceptions.

The presenting symptoms in adult patients with intussusceptions are non-specific and often long standing. Most series report pain as the commonest symptom, being present in $71 \%$ to $90 \%$ of patients, with vomiting and bleeding from the rectum as the next most common symptoms. ${ }^{13}$ The most important characteristic of pain is its periodic, intermittent nature, which makes the diagnosis elusive and accounts for the delay in making the diagnosis, with only half the cases being diagnosed before operation..$^{13}$ Abdominal mass is noted in $24 \%$ to $42 \%$ of cases. ${ }^{9}{ }^{14}$

In the review article by Azar et al, ${ }^{9}$ the mean duration of symptoms between onset and presentation was 37.4 days (range 1-365 days). The duration of symptoms was longer in patients with benign and enteric lesions compared with those with malignant and colonic lesions.

Computed tomography seems to be the most reliable investigation in making a preoperative diagnosis, especially in those patients with non-specific abdominal pain in whom the diagnosis can be elusive. ${ }^{124}$ The appearance of intussusception is characteristic (table 2), and has been confirmed both in experimental models and clinical situations. ${ }^{125} 26$ Interestingly, recent experience with computed tomography/ magnetic resonance imaging has enabled detection of vascular compromise ${ }^{27}$ and it has also been suggested that lesions detected by these investigations are more likely to have non-neoplastic causes. ${ }^{28}$ The accuracy of computed tomography has been confirmed at operation by some studies. ${ }^{129}$ In our study, computed tomography was carried out in three patients and it was diagnostic in two patients. In the third patient (gastroduodenal intussusception), it showed the presence of a mass, suggestive of a lipoma.

Other investigations like ultrasonography, ${ }^{3031}$ barium enema, ${ }^{9}{ }^{10}$ colonoscopy or flexible sigmoidoscopy, ${ }^{32}$ upper GI series, ${ }^{33}$ can be used according to the clinical situation.

Adult intussusception warrants laparotomy rather than attempts at hydrostatic reduction in view of the high incidence of underlying abnormlity. ${ }^{93}$ Controversy remains as to whether reduction of the intussuscepting lesion should be attempted at operation. Early reports advocated reducing the intussusception before resection. ${ }^{3}$ The perceived disadvantage of this is that malignant cells may be disseminated during the process despite no clear evidence on this issue. On the other hand, the advantages of reducing the intussusception especially when the small bowel is affected are that it may be possible to preserve considerable lengths of bowel and thereby prevent development of short bowel syndrome.

Begos et $a l^{23}$ suggest resection without attempting reduction when the bowel is inflamed, ischaemic, or friable and in obvious colo-colic intussusception (given the high likelihood of malignancy). In all other cases reduction should always be attempted initially. However, Azar et al ${ }^{8}$ suggested that surgical resection without reduction is the preferred treatment in adults, as almost $50 \%$ of both colonic and enteric intussusceptions are associated with malignancy. Simple reduction is however acceptable in post-traumatic and idiopathic intussusceptions where no pathological cause is usually present in the bowel. ${ }^{32}$

Treatment of gastroduodenal intussusceptions usually entails reduction of the intussusception and surgical excision of the lead point, either endoscopically or through a formal laparotomy. ${ }^{16}$ In coloanal intussusceptions, the preferred approach is to reduce the intussusception before resection. This could lead to a sphincter saving operation as compared with an abdominoperineal resection. ${ }^{16}$ However, it is not always easy to reduce the intussusception and there is a risk of disseminating cancer cells. Abdominal resection is the preferred method but perineal approaches have also been tried. Our experience with the coloanal and gastroduodenal

\section{Key points}

Table 2 Main computed tomographic findings in patients with adult intussusception

\begin{tabular}{ll}
\hline Finding & Explanation \\
\hline Apparent mass lesion* & $\begin{array}{l}\text { Caused by thickened segment of bowel } \\
\text { (the intussusceptum telescoping into the } \\
\text { intussuscipiens) }\end{array}$ \\
$\begin{array}{l}\text { A crescent-like, eccentric low } \\
\text { attenuation fatty mass* }\end{array}$ & $\begin{array}{l}\text { Represents the entrapped mesenteric fat. } \\
\text { A rim of contrast material } \\
\text { encircling the intussusceptum }\end{array}$ \\
$\begin{array}{l}\text { Rir bubbles } \\
\text { bowel walls of the intussusceptum and } \\
\text { the intussuscipiens. } \\
\text { Occurs peripheral to the upper part of } \\
\text { the intussusception and may lie between } \\
\text { the opposing bowel walls. }\end{array}$ \\
\hline
\end{tabular}

*Combination of these two lesions produces a target or sausage shaped mass. TThis feature is analogous to the coil spring appearance seen on a barium enema.
- Intussusception in adults is an infrequent cause of intestinal obstruction.

- Preoperative diagnosis is difficult as symptoms can be intermittent and long standing.

- More frequent use of computed tomography in undiagnosed abdominal pain increases the pick up rates.

- Surgical treatment is required in all patients and there is more emphasis towards resection without reduction in most cases.

- Innovative surgical techniques may be required in gastroduodenal and coloanal intussusceptions. 
cases shows that the operative procedure may need innovative techniques and can be challenging, especially with the former.

\section{CONCLUSIONS}

Intussusception in adults is an infrequent problem. The diagnosis of this condition can be difficult as symptoms are often non-specific and episodic. It is important to have a high index of suspicion. The most useful investigation is abdominal computed tomography. Treatment requires resection of the involved bowel without attempted reduction in colonic lesions and in small bowel cases where the bowel is nonviable or where malignancy is suspected. With gastroduodenal and coloanal intussusceptions the surgical technique may need modification according to the situation and can be challenging.

\section{Authors' affiliations}

S Yalamarthi, R C Smith, Department of General Surgery, Falkirk District and Royal Infirmary, Falkirk, Scotland

Funding: none.

Conflicts of interest: none declared.

\section{REFERENCES}

1 Gayer G, Apter S, Hofmann C, et al. Intussusception in adults: CT diagnosis. Clin Radiol 1998;53:53-7.

2 Carter CR, Morton AL. Adult intussusception in Glasgow, UK. Br J Surg 1989;76:727.

3 Donhauser DL, Kelly EC. Intussusception in the adult. Am J Surg 1950;79:673-7.

4 Brayton D, Norris WJ. Intussusception in adults. Am J Surg 1954;88:32-43.

5 Gordon RS, O'Dell KB, Namon AJ, et al. Intussusception in adults-a rare disease. J Emerg Med 1991;9:337-42.

6 Barbette P. Ouevres Chirurgiques at Anatomiques. Geneva: Francois Miege, 1674.

7 Hunter J. On introsusception (read Aug 18, 1789). In: Palmer JF, ed. The works of John Hunter, FRS London. London: Longman, Rees, Orme, Brown, Green, Longman, 1837:587-93.

8 Hutchinson J. A successful case of abdominal section for intussusception. Proc R Med Chir Soc 1873;7:195-8.

9 Azar T, Berger DL. Adult intussusception. Ann Surg 1997;226:134-8.

10 Nagomey DM, Sarr MG, Mcllrath DC. Surgical management of intussusception in the adult. Ann Surg 1981;193:230-6.
11 Agha FP. Intussusception in adults. Am J Roentgenol 1986;146:527-31.

12 Adebamowo CA, Akang EE, Pindiga HU, et al. Changing clinicopathological profile of intussusception in Nigeria-a 20 -year review. Hepatogastroenterology 2000:47:437-40.

13 Reijnen HA, Joosten HJ, De Boer HH. Diagnosis and treatment of adult intussusception. Am J Surg 1989;158:25-8.

14 Stubenord WT, Thorblamarson B. Intussusception in adults. Ann Surg 1970;172:306-10.

15 Nesbakken A, Haffner J. Colo-recto-anal intussusception: case report. Acta Chir Scand 1989;155:201-4.

16 Lin F, Setya V, Signor W. Gastroduodenal intussusception secondary to a gastric lipoma: a case report and review of literature. Am Surg 1992:58:772-4.

17 Felix EL, Cohen $M H$, Bernstein $A D$, et al. Adult intussusception: case report of recurrent intussusception and review of the literature. Am J Surg 1976;131:758-61

18 Brooks A, Bebington BD, Lucas $S$, et al. Intussusception caused by blunt abdominal trauma. J Trauma 1999;47:156-7.

19 Eke N, Adotey JM. Post operative intussusception, causal or casual relationship? Int Surg 2000;85:303-8.

20 Dannin JC, McCarty M, Coker R. Case Report: Lymphoma causing small bowel intussusception in a patient with the acquired immune deficiency syndrome. Clin Radiol 1992;46:350-1.

21 Meyerson S, Desai TK, Polidori G, et al. A case of intussusception and lymphoid hyperplasia in a patient with AIDS. Am J Gastroenterol 1993:88:303-6.

22 Weilbaecher D, Bolin JA, Hearn D, et al. Intussusception in adults: Review of 160 cases. Am J Surg 1971;121:531-5.

23 Begos DG, Sandor A, Modlin IM. The diagnosis and management of adult intussusception. Am J Surg 1997;73:88-94.

24 Takeuchi K, Tsuzuki $Y$, Ando $T$, et al. The diagnosis and treatment of adult intussusception. J Clin Gastroenterol 2003;36:18-21.

25 Bar-ZivJ, Solomon A. Computed tomography in adult intussusception. Gastrointest Radiol 1991;16:264-6.

26 Gayer G, Zissin R, Apter S, et al. Pictorial review: adult intussusception-a CT diagnosis. Br J Radiol 2002;75:185-90

27 Fujimoto T, Fukuda T, Uetani M, et al. Unenhanced CT findings of vascular compromise in association with intussusceptions in adults. Am J Roentgenol 2001;176:1167-71.

28 Warshaver DM, Lee JK. Adult intussusception detected at CT or MR imaging: clinical-imaging correlation. Radiology 1999;212:853-60.

29 Barbiera F, Cusma S, Di Giacomo D, et al. Adult intestinal intussusception: surgery-CT correlation. Radiol Med 2001;102:37-42.

30 Boyle MJ, Arkell $\sqcup$, Williams JT. Ultrasonic diagnosis of adult intussusception. Am J Gastroenterol 1993;88:617-18.

$31 \mathrm{Lim} \mathrm{JH}, \mathrm{Ko} \mathrm{JT}$, Lee DH, et al. Determining the site and causes of colonic obstruction with sonography. Am J Roentgenol 1994;163:1113-17.

32 Kitamura K, Kitagawa S, Mori M, et al. Endoscopic correction of intussusception and removal of a colonic lipoma. Gastrointest Endosc 1990;36:509-11

33 Wiot JF, Spitz HB. Small bowel intussusception demonstrated by oral barium. Radiology 1970;97:361-6. 